\title{
MOŻLIWOŚCI ZAGOSPODAROWANIA LOTNEGO POPIOŁU Z TERMICZNEGO PRZEKSZTALCANIA KOMUNALNYCH OSADÓW ŚCIEKOWYCH W ZAWIESINACH TWARDNIEJĄCYCH
}

\author{
Paweł Falaciński® ${ }^{\bowtie}$ Łukasz Szarek \\ Wydział Instalacji Budowlanych, Hydrotechniki i Inżynierii Środowiska, Politechnika Warszawska, Warszawa
}

\begin{abstract}
STRESZCZENIE
W 2014 roku wytworzono 556 tys. ton s.m. komunalnych osadów ściekowych. Jest to pochodna rozwoju cywilizacyjnego Polski i budowy nowoczesnych oczyszczalni ścieków. Zaostrzające się przepisy oraz założone strategiczne cele gospodarki ściekowej determinują rozwój nowoczesnych metod przekształcania osadów ściekowych - technik termicznych. W wyniku takich działań ilość powstałych lotnych popiołów po spaleniu komunalnych osadów ściekowych znacząco rośnie. Trwają intensywne prace nad możliwością bezpiecznego dla środowiska zagospodarowania tego typu odpadu. Artykuł prezentuje wyniki badań podstawowych parametrów technologicznych zawiesin twardniejących z dodatkiem lotnego popiołu z termicznego przekształcania komunalnych osadów ściekowych. Na tej podstawie analizowano przydatność projektowanych zawiesin twardniejących pod kątem możliwości ich zastosowania w realizacji przesłon przeciwfiltracyjnych w wałach przeciwpowodziowych.
\end{abstract}

Słowa kluczowe: zawiesina twardniejąca, lotny popiół z termicznego przekształcania komunalnych osadów ściekowych

\section{WSTĘP}

Od 2004 roku zanotowano wzrost liczby oczyszczalni ścieków komunalnych o ponad 14\% - z 2875 do 3288 w 2014 roku (GUS, 2014). Przyrost obiektów specjalistycznych o wysokiej sprawności technologicznej powoduje dość szybki wzrost produktu ubocznego w procesie oczyszczania ścieków, tj. komunalnych osadów ściekowych. Według danych GUS (2014), ilość wytworzonych komunalnych osadów ściekowych w 2014 roku wyniosła 556,0 tys. ton s.m. Stały, coroczny przyrost ilości komunalnych osadów ściekowych (na poziomie ok. 2,0-2,5\%) stwarza ogromne problemy z bezpiecznym ich zagospodarowaniem.

Jednym ze sposobów przetwarzania powstałych osadów ściekowych jest ich spalanie. W ostatnich latach w Polsce bardzo rozwinęły się metody termiczne, w związku z tym ilość ubocznych produktów spalania - popiołów, znacząco wzrosła. Proces spalania osadów ściekowych nie eliminuje jednak dużej zawartości fosforu oraz metali ciężkich. W związku z tym poszukiwane są sposoby bezpiecznego dla środowiska zagospodarowania/wykorzystania lotnych popiołów z termicznego przekształcania osadów ściekowych (TPOŚ) - Białowiec, Janczukowicz i Krzemieniewski (2009).

Zaprezentowany $\mathrm{w}$ artykule eksperyment miał na celu sprawdzenie możliwości stosowania lotnych popiołów z TPOŚ jako składnika zawiesin twardniejących, wykorzystywanych podczas realizacji przesłon

\footnotetext{
凶pawel.falacinski@is.pw.edu.pl
} 
Falaciński, P. i Szarek, Ł. (2017). Możliwości zagospodarowania lotnego popiołu z termicznego przekształcania komunalnych osadów ściekowych w zawiesinach twardniejących. Acta Sci. Pol. Architectura, 16 (1), 35-42. doi: 10.22630/ASPA.2017.16.1.04.

przeciwfiltracyjnych w obiektach hydrotechnicznych / ochrony środowiska. Przedstawiono badania podstawowych właściwości technologicznych (w stanie płynnym) zawiesin twardniejących.

\section{WŁAŚCIWOŚCI TECHNOLOGICZNE ZAWIESIN TWARDNIEJĄCYCH}

Zgodnie z definicją (PN-EN 1538+A1. 2015-08:2015) zawiesina twardniejąca jest to zawiesina, która twardnieje z upływem czasu i zawiera cement lub inne spoiwo oraz dodatkowe materiały, jak ił (bentonit), granulowany żużel wielkopiecowy lub popioły lotne, wypełniacze i domieszki.

Informacje o właściwościach zawiesin można znaleźć w literaturze przedmiotu (np. Borys, 2008, 2015; Kledyński i Rafalski, 2009), a w odniesieniu do gotowych mieszanek - w aprobatach technicznych wydanych dla tego typu wyrobów (np. ITP, 2011).

Przedstawione w tabeli 1 wartości wybranych właściwości zawiesin twardniejących charakteryzują wymagania w stosunku do przesłon przeciwfiltracyjnych realizowanych (różnymi metodami) w wałach przeciwpowodziowych.

Tabela 1. Wybrane właściwości zawiesin twardniejących stosowanych do wykonywania przesłon przeciwfiltracyjnych w wałach przeciwpowodziowych (IBDiM, 2003; Borys, 2008, 2015)

Table 1. Selected properties of hardening slurries applied during the implementation of the cut-off walls in water embankment (IBDiM, 2003; Borys, 2008, 2015)

\begin{tabular}{|c|c|c|c|}
\hline $\begin{array}{l}\text { Właściwości } \\
\text { Properties }\end{array}$ & $\begin{array}{c}\text { Jednostka } \\
\text { Unit }\end{array}$ & $\begin{array}{l}\text { Wartości } \\
\text { Value }\end{array}$ & $\begin{array}{l}\text { Oznaczenie według } \\
\text { Marked by }\end{array}$ \\
\hline Gęstość - Density & \multirow{4}{*}{$\mathrm{g} \cdot \mathrm{cm}^{-3}$} & & \multirow{4}{*}{$\begin{array}{l}\text { BN-90/1785-01:1990. } \\
\text { Płuczka wiertnicza. Metody badań } \\
\text { w warunkach polowych }\end{array}$} \\
\hline $\begin{array}{l}\text { - metoda wgłębnego mieszania (DSM) } \\
\text { deep soil mixing method (DSM) }\end{array}$ & & $1,30-1,50$ & \\
\hline $\begin{array}{l}\text { - metoda wibracyjna (WIPS) } \\
\text { vibro injected thin-wall method (WIPS) }\end{array}$ & & $1,50-1,60$ & \\
\hline $\begin{array}{l}\text { - metoda wykopu wąskoprzestrzennego } \\
\text { narrow spatial excavation method }\end{array}$ & & $1,15-1,40$ & \\
\hline $\begin{array}{l}\text { Lepkość umowna (czas wypływu z lejka Marsha) } \\
\text { Conventional viscosity (the time of flow from } \\
\text { Marsh funnel) }\end{array}$ & $\mathrm{s}$ & $\begin{array}{l}\text { maks. } 50 \\
\text { max. } 50\end{array}$ & BN-90/1785-01:1990 \\
\hline $\begin{array}{l}\text { Odstój dobowy wody (po } 24 \text { h) } \\
24 \text { h water setting }\end{array}$ & $\%$ & $\begin{array}{c}\text { maks. } 4 \\
\max .4\end{array}$ & $\begin{array}{l}\text { PN-85/G-02320:1985. } \\
\text { Wiertnictwo. Cementy i zaczyny cementowe } \\
\text { do cementowania w otworach wiertniczych }\end{array}$ \\
\hline $\begin{array}{l}\text { Wytrzymałość strukturalna (po } 10 \mathrm{~min} \text { ) } \\
\text { Structural strength (po } 10 \mathrm{~min} \text { ) }\end{array}$ & $\mathrm{Pa}$ & $1,4-10,0$ & BN-90/1785-01:1990 \\
\hline
\end{tabular}

\section{MATERIA I METODY}

\section{Ogólna charakterystyka popiołu z TPOŚ zastosowanego w eksperymencie}

Popiół z TPOŚ powstaje poprzez spalanie osadów ściekowych w wysokiej temperaturze (ok. $600-920^{\circ} \mathrm{C}$ ), gdzie następuje znaczne zmniejszenie objętości materiału przy jednoczesnym uzysku energii cieplnej. Ze względu na dużą zawartość substancji organicznych w osadzie ściekowym popioły z TPOŚ mogą zawierać 
0,3-1,5\% fosforu ogólnego (Łukawska, 2014). Wpływa to negatywnie na opóźnienie procesu hydratacji cementu w betonach na bazie tego dodatku (Małolepszy i Tkaczewska, 2006). W tabeli 2 przedstawiono wybrane właściwości fizyczne popiołu z TPOŚ zastosowanego w eksperymencie.

Analizowane popioły charakteryzują się zróżnicowanym składem ziarnowym, o czym świadczy powierzchnia właściwa, wahającą się w zakresie $2560-3670 \mathrm{~cm}^{2} \cdot \mathrm{g}^{-1}$ (zmienność ok. 30\% dla 3 dostarczonych partii). Cecha ta wraz ze znaczną wartością miałkości (47,0-62,5\% masy) ma duży wpływ m.in. na zapotrzebowanie popiołu na wodę, co potwierdzają wyniki badań wodożądności (129-132\% w odniesieniu do cementu porównawczego CEM I 42,5R).

Tabela 2. Wybrane właściwości fizyczne popiołu z TPOŚ (Falaciński i Szarek, 2016)

Table 2. Selected physical properties of ash from the thermal utilization of municipal sewage sludge (Falaciński i Szarek, 2016)

\begin{tabular}{lcc}
\hline Właściwości - Properties & $\begin{array}{c}\text { Jednostka } \\
\text { Unit }\end{array}$ & $\begin{array}{c}\text { Wartości } \\
\text { Value }\end{array}$ \\
\hline Powierzchnia właściwa - Specific surface area & $\mathrm{cm}^{2} \cdot \mathrm{g}^{-1}$ & $2560-3670$ \\
Gęstość - Density & $\mathrm{Mg} \cdot \mathrm{m}^{-3}$ & $2260-2360$ \\
Wodożądność - Water demand & $\%$ & $129-132$ \\
Wskaźnik aktywności - Activity index & $\%$ & $54,0-66,5$ \\
& $\%$ masy & $47,0-62,5$ \\
Miałkość - Initial setting time & $\%$ mass & \\
\hline
\end{tabular}

Otrzymane wyniki badań wskaźnika aktywności po 28 dniach dojrzewania próbek zawierających popiół z TPOŚ (54,0-66,5\% w odniesieniu do cementu porównawczego CEM I 42,5R) świadczą o małej aktywności pucolanowej materiału.

W świetle przytoczonych wyników badań (tab. 2) oraz zawartości fosforu (Łukawska, 2014) popioły z TPOŚ można klasyfikować jako materiał o małej przydatności w szeroko rozumianym budownictwie. Wysoka wodożądność oraz mała aktywność eliminują go jako dodatek do betonu, jednak otwierają możliwość wykorzystania w zawiesinach twardniejących, gdzie stosunek w/s (woda/suche składniki), a także wynikająca z niego wytrzymałość, nie są tak znaczące.

\section{RECEPTURY ZAWIESIN TWARDNIEJĄCYCH}

Do sporządzenia zawiesin twardniejących wykorzystano: wodę wodociągową, bentonit sodowy, cement CEM I 32,5R i lotny popiół z TPOŚ. Na rysunku 1 przedstawiono udział składników w ujęciu procentowym na $1 \mathrm{~m}^{3}$ zawiesiny badanych receptur zawiesin twardniejących (od R1 do R10).

\section{Badania właściwości płynnych (technologicznych)}

Pomiaru gęstości $(\rho)$ zawiesiny twardniejącej w stanie płynnym dokonano przy użyciu wagi płuczkowej typu Baroid (BN-90/1785-01:1990).

Lepkość umowną ( $L$ ) zawiesiny badano przy użyciu wiskozymetru wypływowego (lejek Marsha). Mierzono czas (w sekundach) wypływu $1000 \mathrm{ml}$ płynnej zawiesiny (z $1500 \mathrm{ml}$ zawiesiny umieszczonej w lejku) do naczynia cechowanego (BN-90/1785-0:1990). 


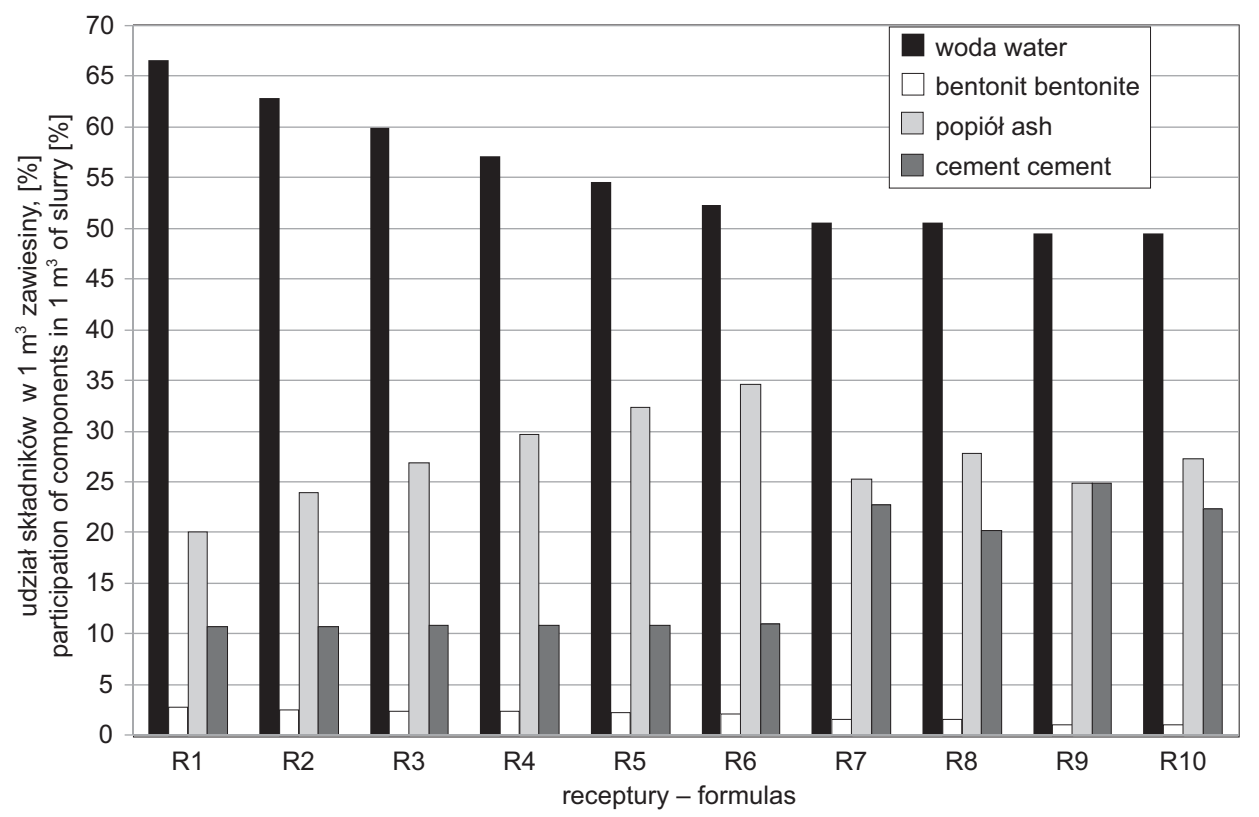

Rys. 1. Procentowy udział składników w $1,0 \mathrm{~m}^{3}$ zawiesiny

Fig. 1. The percentage of components in $1,0 \mathrm{~m}^{3}$ of slurry

Pomiar odstoju dobowego wody $\left(O_{d}\right)$ określano jako procentowy udział objętości wody wydzielającej się samoistnie z $1,0 \mathrm{dm}^{3}$ zawiesiny po określonym czasie pozostawienia jej w bezruchu w cylindrze pomiarowym (PN-85/G-02320:1985).

Oznaczenie wytrzymałości strukturalnej $(\tau)$ zawiesiny płynnej wykonano za pomocą szirometru (BN-90/1785-01:1990).

\section{WYNIKI I DYSKUSJA}

Wartości parametrów technologicznych badanych zawiesin twardniejących przedstawiono na rysunkach 2-5 w odniesieniu do wskaźników: w/s (woda/suche składniki) oraz w/c (woda/cement).

Analizę otrzymanych parametrów przeprowadzono w odniesieniu do wymagań prezentowanych w tabeli 1 właściwości technologicznych zawiesin twardniejących stosowanych do wykonywania przesłon przeciwfiltracyjnych w wałach przeciwpowodziowych.

Analizując gęstość (rys. 2), należy zauważyć, iż jej wartość jest na poziomie wystarczającym do zapewnienia stateczności głębionego wykopu (oprócz metody WIPS) dla badanych receptur z wyłączeniem R1 (dla metody DSM). Wartość gęstości zawiesin rośnie wraz ze spadkiem wskaźnika w/s oraz w/c.

Lepkość umowna receptur R5 i R6 przekracza wartości dopuszczalne (szacowane na maks. 50 s) ze względu na możliwość transportu hydraulicznego zawiesiny w miejsce wbudowania oraz jej przemieszczanie w drążonym wykopie. Trend wzrostu wartości lepkości umownej jest - generalnie - odwrotnie proporcjonalny do wzrostu wskaźników w/c i w/s (rys. 3).

Odnotowane wartości odstoju wody po dwóch godzinach spełniają wyznaczone kryterium (maks. 4,0\%) dla receptur R4-R10. W stosunku do odstoju określonego po 24 godzinach (dobowego) kryterium dopuszczalne spełniły jedynie receptury R9 i R10 (rys. 4). Spadek wartości odstoju po 2 i 24 godzinach jest proporcjonalny do spadku wskaźników w/s i w/c. 


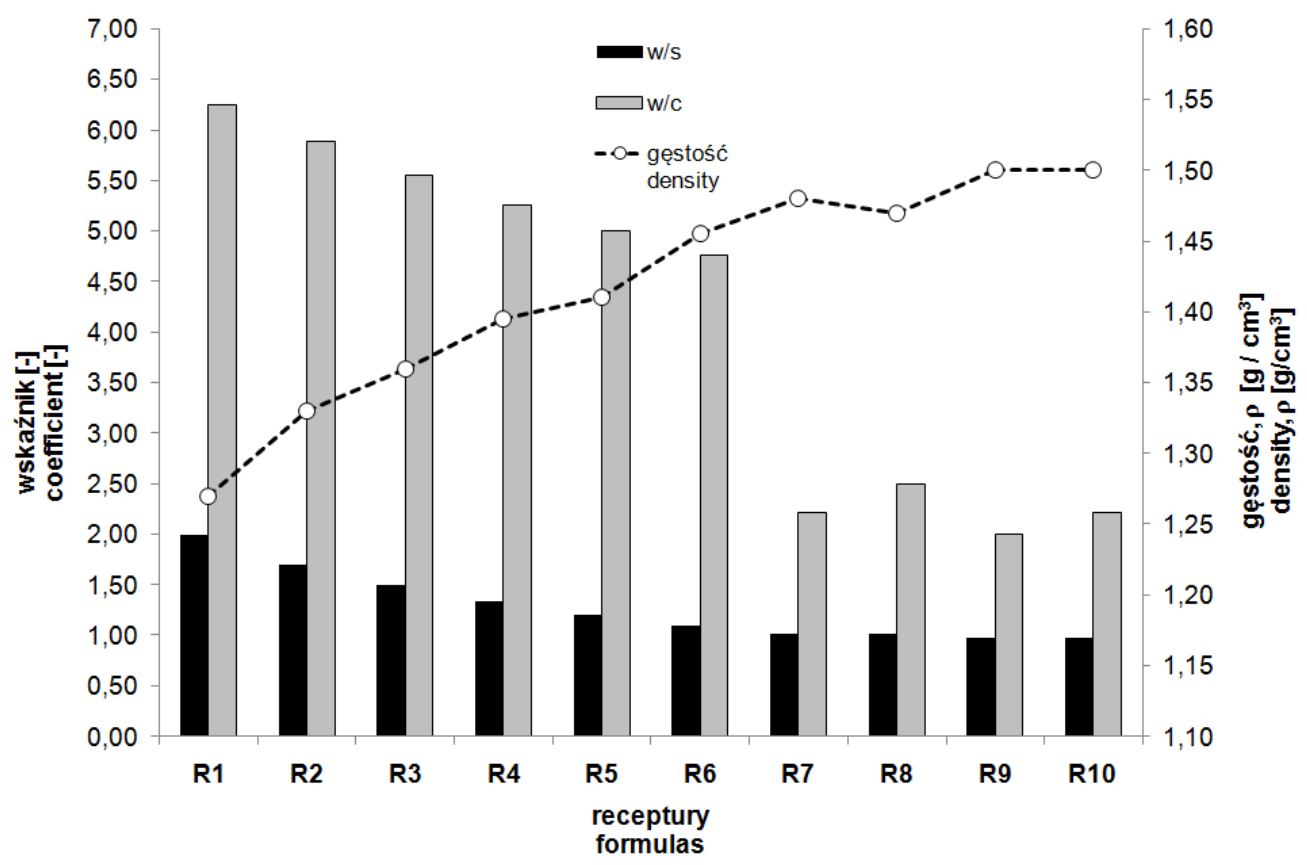

Rys. 2. Zależność gęstości od wskaźników w/s oraz w/c

Fig. 2. Density dependence coefficients $\mathrm{w} / \mathrm{s}$ and $\mathrm{w} / \mathrm{c}$

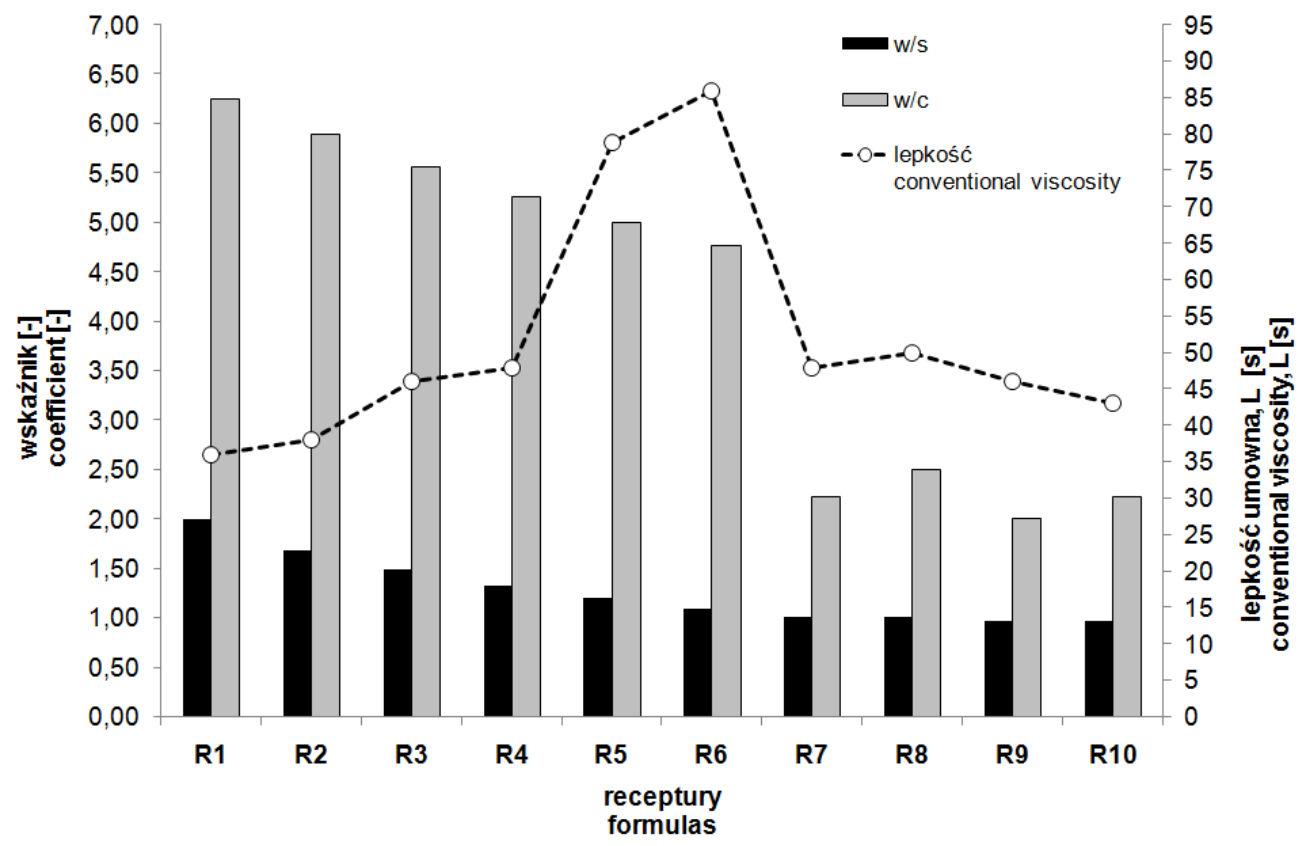

Rys. 3. Zależność lepkości umownej od wskaźników w/s oraz w/c

Fig. 3. Conventional viscosity dependence coefficients $w / s$ and $w / c$ 


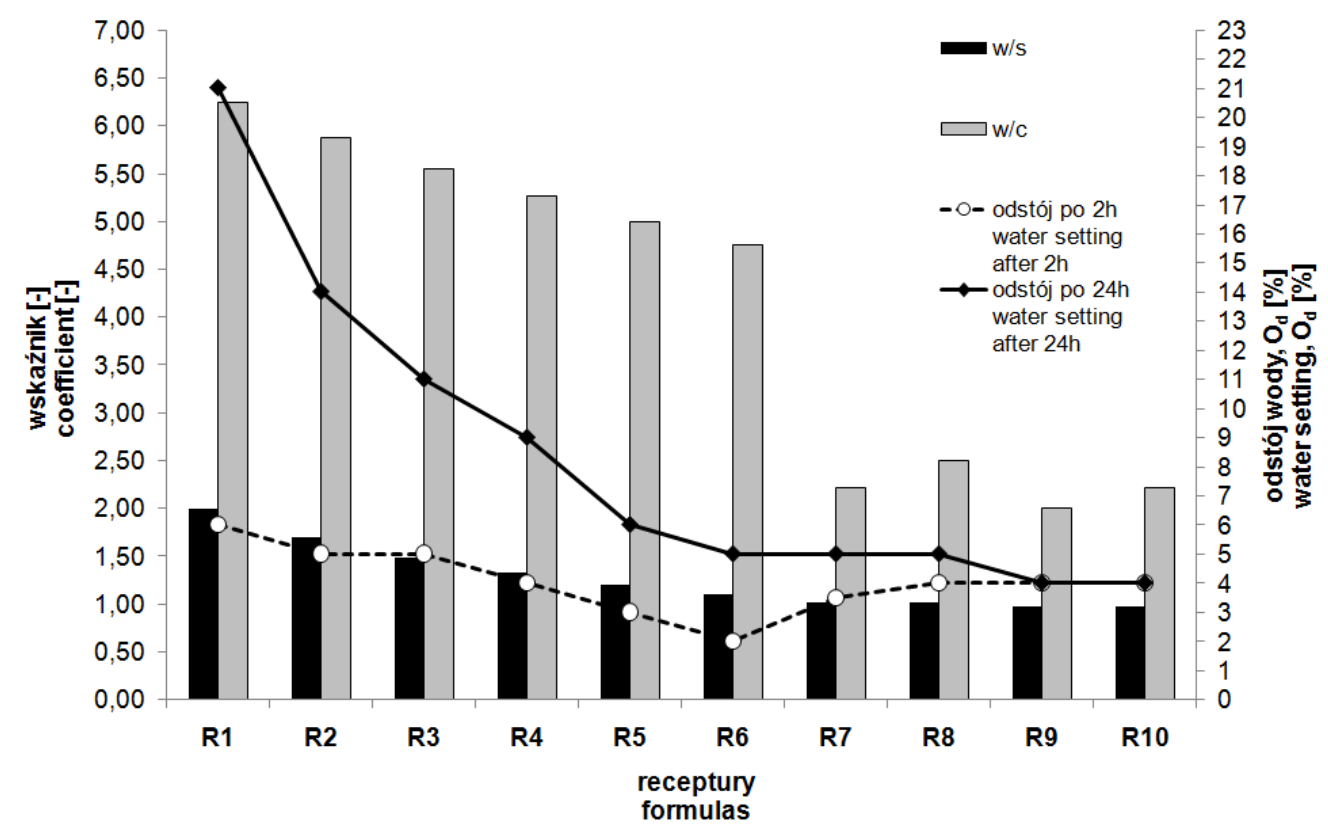

Rys. 4. Zależność odstoju wody od wskaźników w/s oraz w/c

Fig. 4. Water setting dependence coefficients: $w / s$ and $w / c$

Wartość dopuszczalną wytrzymałości strukturalnej (po 10 minutach, powyżej 1,4 Pa - IBDiM, 2003) osiągnęły wszystkie receptury z wyłączeniem R1 i R2 (rys. 5).

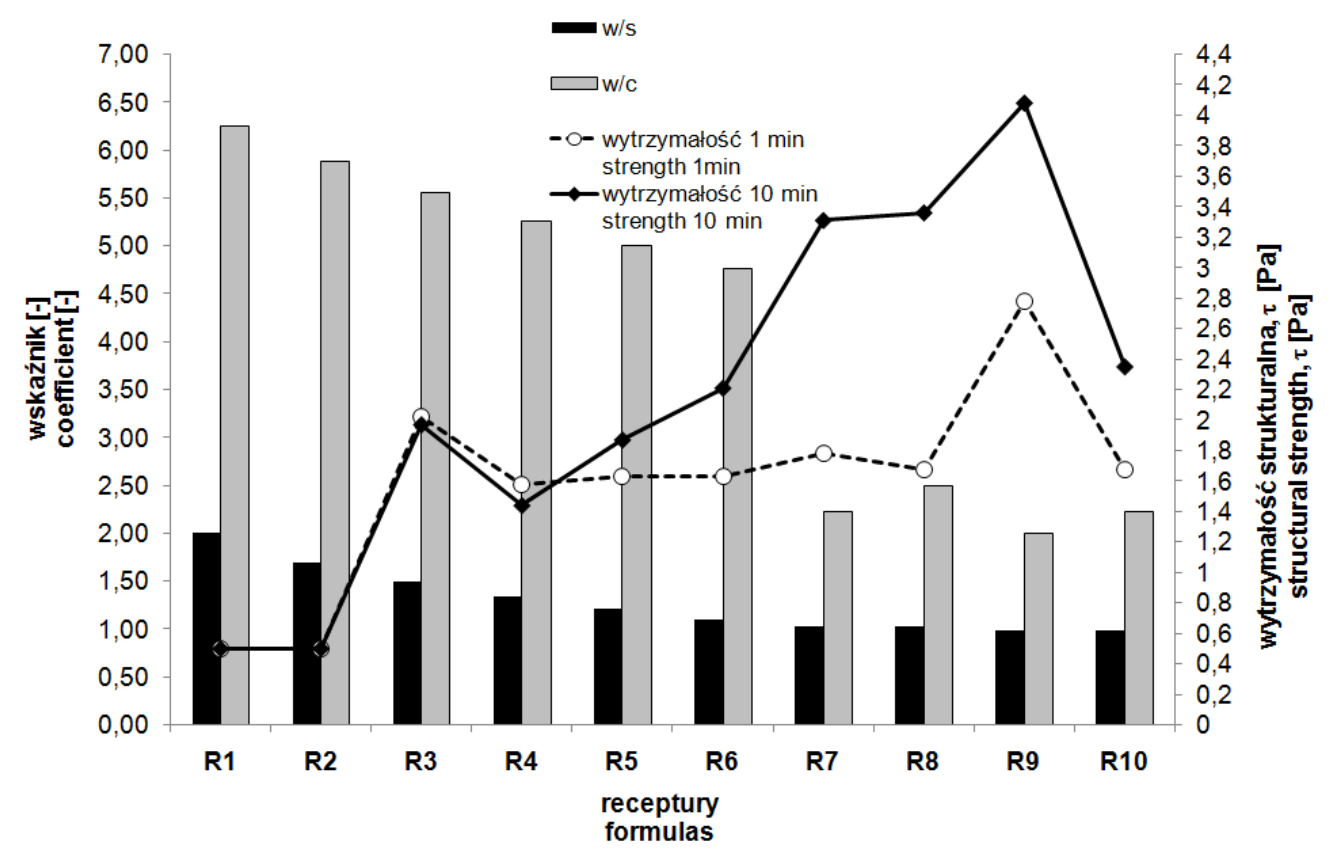

Rys. 5. Zależność wytrzymałości stukturalnej od wskaźników w/s oraz w/c

Fig. 5. Structural strength dependence coefficients $w / s$ and $w / c$ 


\title{
PODSUMOWANIE
}

Biorąc pod uwagę analizowane parametry technologiczne, należy zauważyć, iż wszystkie założone kryteria w odniesieniu do zawiesin twardniejących stosowanych podczas realizacji uszczelnień wałów przeciwpowodziowych spełniły jedynie receptury R9 i R10.

Kolejnym etapem badań będzie testowanie przydatności akceptowalnych receptur pod kątem ich parametrów użytkowych (po stwardnieniu).

Uzyskane podczas eksperymentu wyniki wskazują na istniejący potencjał zastosowania lotnego popiołu z termicznego przekształcania komunalnych osadów ściekowych jako dodatku do zawiesin twardniejących.

\section{PIŚMIENNICTWO}

Białowiec A., Janczukowicz W. i Krzemieniewski M. (2009). Możliwości zagospodarowania popiołów po termicznym unieszkodliwianiu osadów ściekowych w aspekcie regulacji prawnych. Roczniki Ochrony Środowiska, 11, 959-971.

BN-90/1785-01:1990. Płuczka wiertnicza. Metody badań w warunkach polowych.

Borys, M. (2008). Wytyczne wykonawstwa pionowych przegród przeciwfiltracyjnych z zawiesin twardniejących w korpusach i podłożu wałów przeciwpowodziowych. Materiały instruktażowe. Procedury 125/9. Falenty: Wydawnictwo IMUZ.

Borys, M. (2015). Projekt wytycznych wykonywania pionowych przegród przeciwfiltracyjnych z zawiesin twardniejących w wałach przeciwpowodziowych. Wiadomości Melioracyjne i Łąkarskie, 3, 126-136.

Falaciński, P. i Szarek, Ł. (2016). Possible applications of hardening slurries with fly ash from thermal treatment of municipal sewage sludge in environmental protection structures. Archives of Hydro-Engineering and Environmental Mechanics, 63(1), 47-61. doi: 10.1515/heem-2016-0004.

Główny Urząd Statystyczny [GUS] (2014). Ochrona środowiska 2014. Warszawa.

Instytut Badawczy Dróg i Mostów [IBDiM] (2003). Warunki techniczne wykonywania ścian szczelinowych. Warszawa: IBDiM.

Instytut Technologiczno-Przyrodniczy [ITP] (2011). Aprobata techniczna ITP. AT/18-2011-0052-00. Falenty: Instytut Technologiczno-Przyrodniczy.

Kledyński, Z. i Rafalski, L. (2009). Zawiesiny twardniejące. Warszawa: KILiW PAN, IPPT PAN.

Łukawska, M. (2014). Analiza specjacyjna fosforu w osadach ściekowych po termicznym spaleniu. Inżynieria i Ochrona Środowiska, 17(3), 433-439.

Małolepszy, J. i Tkaczewska, E. (2006). Wpływ popiołów lotnych ze współspalania węgla kamiennego i biomasy na proces hydratacji i właściwości cementu. W Materiały IX Konferencji „Dni betonu”, Wisła, 10-12 października 2016 r. (strony 591-601).

PN-85/G-02320:1985. Wiertnictwo. Cementy i zaczyny cementowe do cementowania w otworach wiertniczych.

PN-EN 1538+A1. 2015-08:2015. Wykonawstwo specjalnych robót geotechnicznych. Ściany szczelinowe.

\section{POSSIBILITIES OF FLY ASH FROM THERMAL TREATMENT OF MUNICIPAL SEWAGE SLUDGE IN HARDENING SLURRIES}

\begin{abstract}
In recent years there has been a rapid increase in by-products in the purification of waste water treatment - sewage sludge. It is a derivative of Polish civilization development and construction of modern sewage treatment plants. More stringent regulations and established strategic goals wastewater determine the development of modern methods of disposal of sewage sludge: thermal techniques. As a result of such actions amount resulting fly ash from thermal treatment of municipal sewage sludge has been growing significantly. Intensive work on the possibility of environmentally safe development of this type of waste. The article
\end{abstract}


Falaciński, P. i Szarek, Ł. (2017). Możliwości zagospodarowania lotnego popiołu z termicznego przekształcania komunalnych osadów ściekowych w zawiesinach twardniejących. Acta Sci. Pol. Architectura, 16 (1), 35-42. doi: 10.22630/ASPA.2017.16.1.04.

presents the results of technological parameters of hardening slurries with the addition of fly ash from thermal treatment of municipal sewage sludge. As a comparative criterion applicable requirements in relation to slurries applied during the implementation of the cut-off walls in water embankment.

Key words: hardening slurry, fly ash from thermal treatment of municipal sewage sludge 